\title{
Die Koordinierung zwischen Umweltschutz und Freihandel im Mehrebenenrechtsverbund am Beispiel des Vergaberechts
}

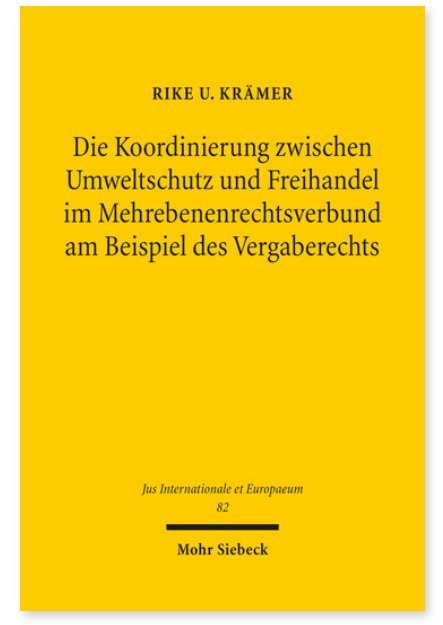

2013. XIV, 235 Seiten. JusIntEu 82

ISBN 978-3-16-152930-6

DOI 10.1628/978-3-16-152930-6

eBook PDF 79,00€

ISBN 978-3-16-152735-7

fadengeheftete Broschur 79,00€
Das Spannungsverhältnis zwischen dem Schutz der Umwelt und der Förderung des Freihandels ist komplex. Es lässt sich nicht einfach mit dem Vorrang des einen Gutes vor dem anderen lösen, sondern erfordert Koordinierung. Im Mehrebenenrechtsverbund, in dem Rechtspluralismus herrscht, müssen nicht nur die beiden Ziele Freihandel vs.

Umweltschutz, sondern auch die verschiedenen Ebenen miteinander koordiniert werden. Rike U. Krämer stellt eine neue Perspektive für diese Koordinierung im Recht dar: das Kollisionenrecht. Dieses Kollisionenrecht bietet normative Maßstäbe zur Koordinierung dieser Zielkonflikte durch Gerichte/Streitbeilegungsgremien und die Administrative.

Die theoretischen Grundlagen des Kollisionenrechts werden am Beispiel des europäischen und des welthandelsrechtlichen Vergaberechtsregimes entfaltet.

Rike U. Krämer Geboren 1981; Studium der Rechts- und Politikwissenschaften in Bremen und Groningen (NL); Referendariat am OLG Bremen; Wissenschaftliche Mitarbeiterin am Sonderforschungsbereich »Staatlichkeit im Wandel« der Universität Bremen; 2011-12 Emile Noël Fellow am Jean Monnet Centre der New York University; seit September 2012 DAAD-Fachlektorin am University College London.

Jetzt bestellen:

https://mohrsiebeck.com/buch/die-koordinierung-zwischen-umweltschutz-und-freihandel-im-mehrebenenrechtsverbundam-beispiel-des-vergaberechts-9783161529306?no_cache=1

order@mohrsiebeck.com

Telefon: +49 (0)7071-923-17

Telefax: +49 (0)7071-51104 